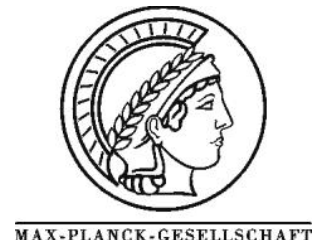

Originally published as:

"SELECTIVITY OF HYDROGEN CHEMISORPTION ON CLEAN AND LEAD MODIFIED PALLADIUM PARTICLES; A TPD AND PHOTOEMISSION STUDY"

Z, PAAL, G. LOOSE, G. WEINBERG, M. REBHOLZ and R. SCHLÖGL

Catalysis Letters 6 (1990) 301-315

doi: 10.1007/BF00763996 


\title{
SELECTIVITY OF HYDROGEN CHEMISORPTION ON CLEAN AND LEAD MODIFIED PALLADIUM PARTICLES; A TPD AND PHOTOEMISSION STUDY
}

\author{
Z. PAAL ${ }^{a}$, G. LOOSE, G. WEINBERG, M. REBHOLZ ${ }^{\mathrm{b}}$ and R. SCHLÖGL ${ }^{*, c}$ \\ Fritz-Haber-Institut der Max-Planck-Gesellschaft, Faradayweg 4-6, D-1000 Berlin 33, Germany \\ * Institut für Anorganische Chemie der Universität Frankfurt, Niederurseler Hang, \\ D-6000 Frankfurt/Main 50, Germany
}

Received 18 May 1990; accepted 10 September 1990

Palladium, hydrogen chemisorption, decomposition of PdO, Head as surface modifier, XPS, UPS, TFD

This work describes hydrogen chemisorption on clean and lead modified palladium particles obtained from decomposition of PdO. TPD is used as a chemical probe to test the surface properties of several states of metallic palladium relevant in practical selective hydrogenation catalysts. These states differ in oxygen content and the presence of a lead modifier. XPS and UPS data serve as a basis for identifying the surface properties. TPD spectra show a very broad low temperature peak-likely bulk hydride decomposition-and a sharp TPD peak between 330 and $380 \mathrm{~K}$. This latter can be devided into three rather poorly separated subpeaks; addition of $\mathrm{Pb}$ does not shift peak maxima but decreases the central subpeak and eliminates the high temperature peak completely. This points to the interaction of $\mathrm{Pb}$ with specific surface sites rather than to bulk alloy formation.

The enhancement of selectivity in hydrogenation obtained from lead modification is considered as a geometric site blocking effect rather than to arise from a bulk modification of the valence electronic structure of palladium metal.

\section{Introduction}

Metallic Pd particles are widely used as hydrogenation catalysts. Activity and in particular selectivity can be fine tuned by modifying preparation condition and by adding modifiers such as $\mathrm{Pb}$ as it is done in the Lindlar catalyst [1]. Hydrogen chemisorption properties depend strongly on the electronic structure of $\mathrm{Pd}$ in the vicinity of the Fermi edge [2]. Impurities such as dissolved oxygen in the metal will thus influence the chemisorption properties.

${ }^{a}$ On leave from Institute of Isotopes of the Hungarian Academy of Sciences, Budapest, Hungary.

${ }^{b}$ Present address: Eidgenössische Fechnische Hochschule, Zürich, Switzerland.

${ }^{c}$ To whom correspondence should be addressed. 
This work is aimed to produce Pd particles in-situ of a UHV surface analysis system and of an atmospheric pressure TPD apparatus and to study the valence electronic structure of "clean" and $\mathrm{Pb}$ modified particles together with the $\mathrm{H}_{2}$ chemisorption.

Temperature Programmed Desorption (TPD) can be used as a chemical probe for characterizing adsorption/desorption properties of catalysts [3]. In spite of the high practical importance of Pd catalysts in hydrogenation reactions [4], no unambiguous data can be found on the TPD of hydrogen from various Pd catalysts. Aldag and Smith [5] found three not well separated desorption peaks from a Pd wire $(T=450-850 \mathrm{~K}$ at lowest coverages shifted to $350-650 \mathrm{~K}$ at higher ones). Babenkova et al. [6] reported a broad peak desorbing from Pd-black at room temperature without heating (dissolved hydrogen) followed by a two-peak system with maxima at 550 and $690 \mathrm{~K}$; the vast majority of hydrogen left their Pd-black catalyst, with maximum desorption rate at $407 \mathrm{~K}$; two minor peaks at 643 and $780 \mathrm{~K}$ finished the TPD spectrum. The sharp peak followed directly by a broader one has also been reported from $\mathrm{Pd}(110)$ single crystal; at a hydrogen loading temperature at $120 \mathrm{~K}$, the first sharp peak appeared at $160 \mathrm{~K}$, followed at somewhat higher coverages by a second one at $230 \mathrm{~K}$; the broad maximum being around $300 \mathrm{~K}$ [8]. Loading $\mathrm{Pd}(100)$ with hydrogen at $170 \mathrm{~K}$ [9], resulted in a double beta-peak with maxima at 370 and $260 \mathrm{~K}$, respectively (the latter appearing with higher coverages only); no alpha-peak appeared.

Apart from the very different temperatures for peak maxima $(260$ to $550 \mathrm{~K})$, it seems likely that the main hydrogen desorption peak is what was called beta $[8,9]$ or B [7] and which consists, likely, of more subpeaks.

Controversial explanations can be found in the literature on the role of the $\mathrm{Pb}$ additive in the Lindlar catalyst. It was suggested that $\mathrm{Pb}$ creates an alloy with $\mathrm{Pb}$ [11] and acts as electronic promoter or that it acts as surface modifier and exerts its effect by blocking certain sites responsible for nonselective hydrogenation [12].

\section{Experimental}

A home-made TPD apparatus was used. The Pyrex glass reactor resembled to the construction II, described in ref. [3] and was heated by a stainless steel furnace block equipped with an external heating coil. The temperature was controlled by a Stanton Redcroft 706 temperature programmer. The temperature change was strictly linear both in the furnace block and in the middle of the tubular reactor with a difference in absolute temperature of $8 \mathrm{~K}$ between the center of the catalyst bed and the furnace block. A Carlo Erba thermal conductiv-

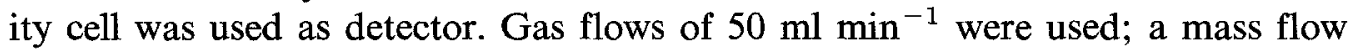
controller by HITEC (Model F 201C-FD) permitted to feed one or two of the following four gases into the furnace with arbitrary mixing ratios: $\mathrm{He}$, alone or with $\mathrm{O}_{2}$ or Ar alone or with $\mathrm{H}_{2}$. The detector signal was recorded by an $X-Y$ 
recorder, the $X$-axis being the temperature of a Chromel-Alumel thermocouple (either directly or through a temperature amplifier/linearizer), the $Y$-axis is the detector signal.

PdO (FLUKA puriss.) was used for the experiments as received. Lead loading was done in a $5 \%$ aqueous solution of $\mathrm{Pb}$ (II) acetate at $300 \mathrm{~K}$ and 12 hours reaction time followed by filtration and drying at $80^{\circ} \mathrm{C}$ for 24 hours.

Scanning Electron Microscopy was carried out in a Hitachi S-4000 instrument at $10 \mathrm{kV}$ voltage. A LINK System 290 was used for EDAX analysis; identification was based on $\mathrm{Pd}-\mathrm{L}$ and $\mathrm{Pb}-\mathrm{L}$ transitions.

Photoemission experiments were carried out in a Leybold LHS 12 apparatus equipped with sources for $\mathrm{X}$ rays $\left(\mathrm{Mg} \mathrm{K}_{\alpha}, 150 \mathrm{~W}, \mathrm{Au} 4 \mathrm{f}=84.0 \mathrm{eV}\right.$ ) and UPS ( $\mathrm{He}$ $\mathrm{I}, 21.22 \mathrm{eV}, 100 \mathrm{~mA}$ discharge current, analyser in retarding ratio $=4$ mode). Loose samples were manipulated on a hot/cold/stage in a preparation chamber allowing gas treatments up to atmospheric pressure. The pressure of the main analyzer chamber with the sample loaded was $10^{-9}$ mbar resulting from an excessive hydrogen background from the sample.

\section{Results}

\section{DECOMPOSITION OF PdO}

PdO reacted with $\mathrm{H}_{2}$ already at room temperature, in agreement with literature data reporting a rapid and complete reduction at $300 \mathrm{~K}$ [13].

When heated in He, PdO decomposed in three steps, with maxima around $370-380$ and $520-530$ and $660 \mathrm{~K}$ (fig. 1, curve 2). Using a liquid $\mathrm{N}_{2}$ trap in the gas line, the first peak disappeared; this indicates that it involved the evolution of water. The remaining second peak arises from oxygen evolution. A second saturation of the once decomposed $\mathrm{PdO}$ with oxygen at $723 \mathrm{~K}$ state did not restore $\mathrm{PdO}$; decomposition in $\mathrm{He}$ up to $753 \mathrm{~K}$ showed only a minor desorption peak around $680 \mathrm{~K}$ (fig. 1, curve 1). This broad desorption peak is rather close to the third peak observed during the initial PdO decomposition $(660 \mathrm{~K})$. Exposure of the Pd particles to oxygen did not lead to the formation of PdO; oxygen uptake stopped at the stage of a $\mathrm{Pd}+\mathrm{O}$ solid solution. This state is intermediate between pure metal and oxide and is obtained when under the influence of the "high" partial pressure of oxygen chemisorbed surface atoms diffuse into the bulk of the metal.

The corresponding UPS experiment is shown in fig. 2. Pd particles originating from in-situ decomposition of $\mathrm{PdO}$ were exposed in-situ to oxygen and heated to various temperatures. At low temperature, a chemisorbed overlayer weakens the $\mathrm{Pd}$ valence band spectrum dominated by the $\mathrm{Pd} 4 \mathrm{f}$ states. This species brings about an $\mathrm{O} 2 \mathrm{p}$ peak at about $6 \mathrm{eV}$; the additional intensity increase at 8.5 and $11.5 \mathrm{eV}$ (broad) indicates the presence $\mathrm{OH}$ groups. The overlayer is desorbed 


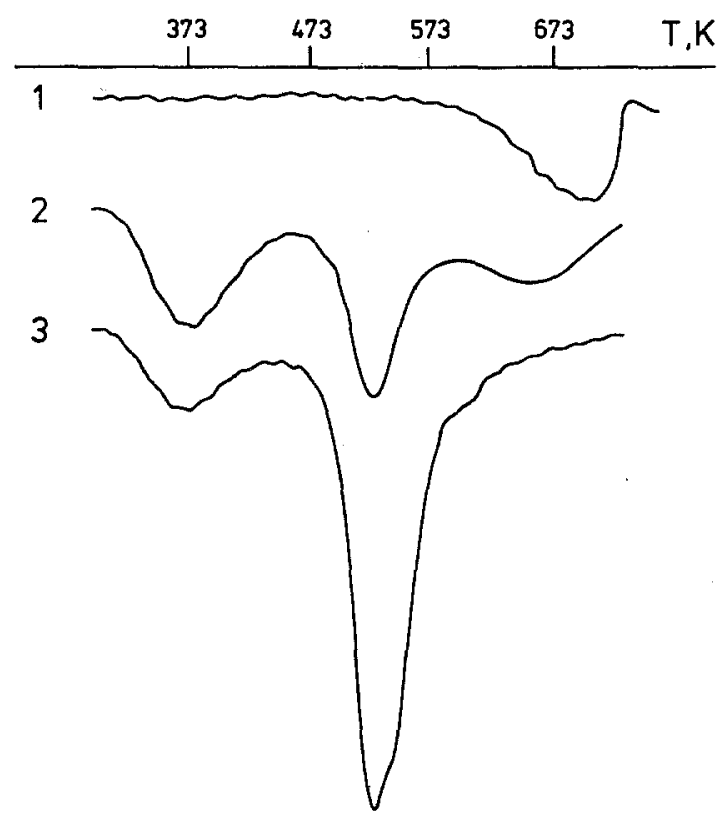

Fig. 1. Decomposition of PdO in He atmosphere. Curve 1: Oxygen desorption from decomposed $\mathrm{PdO}$ saturated with oxygen (1 bar) up to $723 \mathrm{~K}$; Curve 2:-decomposition of PdO; Curve 3: decomposition of $\mathrm{PdO}+\mathrm{Pb}$ acetate. The sensitivity for curve 1 was 8 times larger than for the curves 2 and 3.

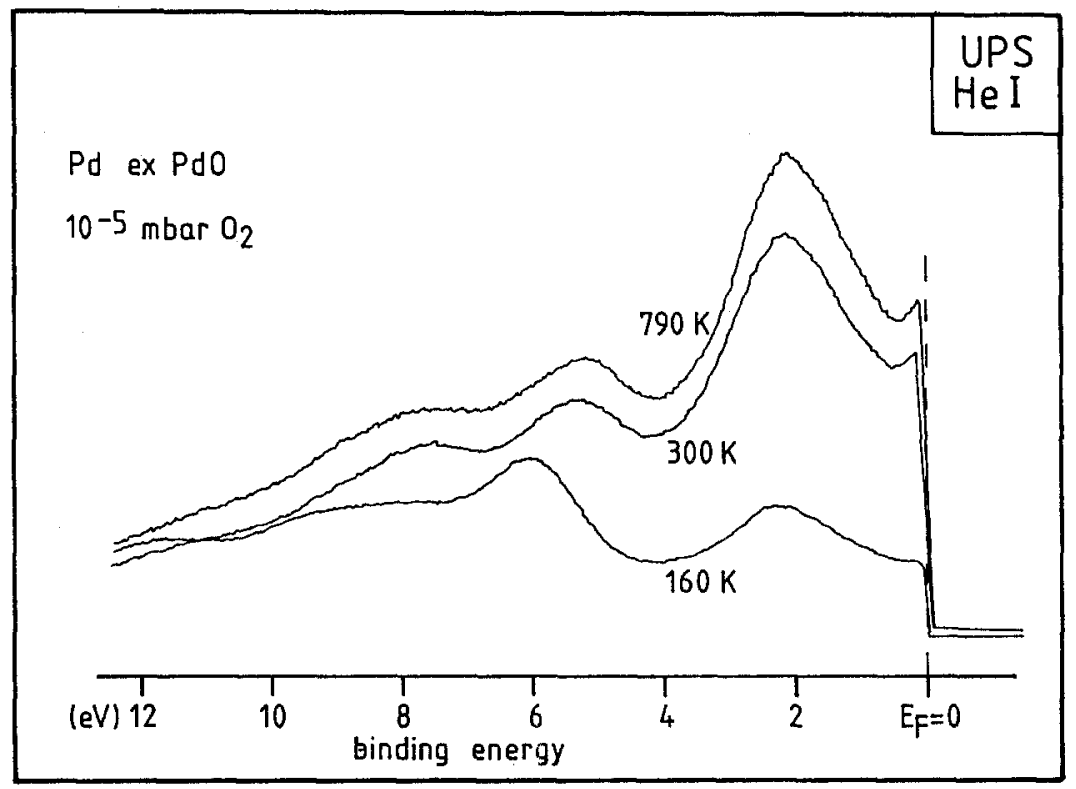

Fig. 2. He I UPS of Pd particles ex PdO decomposition heated in-situ under oxygen. 
upon heating; at the same time, oxygen does not oxidise Pd to PdO as can be seen from the high intensity at the Fermi edge (spectra of Pd oxide, see fig. 3b). The peak at $6 \mathrm{eV}$ shifts to lower $\mathrm{BE}$ and a new feature at $8 \mathrm{eV}$ appears which we ascribe to the $\mathrm{Pd}+\mathrm{O}$ solid solution. It is pointed out that the $\mathrm{Pd}$ in this state is not entirely reduced since this should result in a Fermi edge as high as the Pd $4 \mathrm{~d}$ band maximum [12,14]. The missing intensity near the Fermi edge is transformed by bonding interaction with $\mathrm{O} 2 \mathrm{p}$ to the high $\mathrm{BE}$ peaks. A more detailed analysis of the oxygen species requires He II spectra which were difficult to obtain from the weakly emitting polycrystalline powder samples under these highly unusual experimental conditions. These conditions were chosen to simulate as closely as possible the TPD experiments. It is pointed out that the UPS features do not arise from heavy carbon contamination of the surface; only a few at $\%$ of carbon are present at the surface after initial decomposition. Surface impurities of sulfur and silica amount to ca. 3 at $\%$ and remain unaffected by any treatment after the initial decomposition.

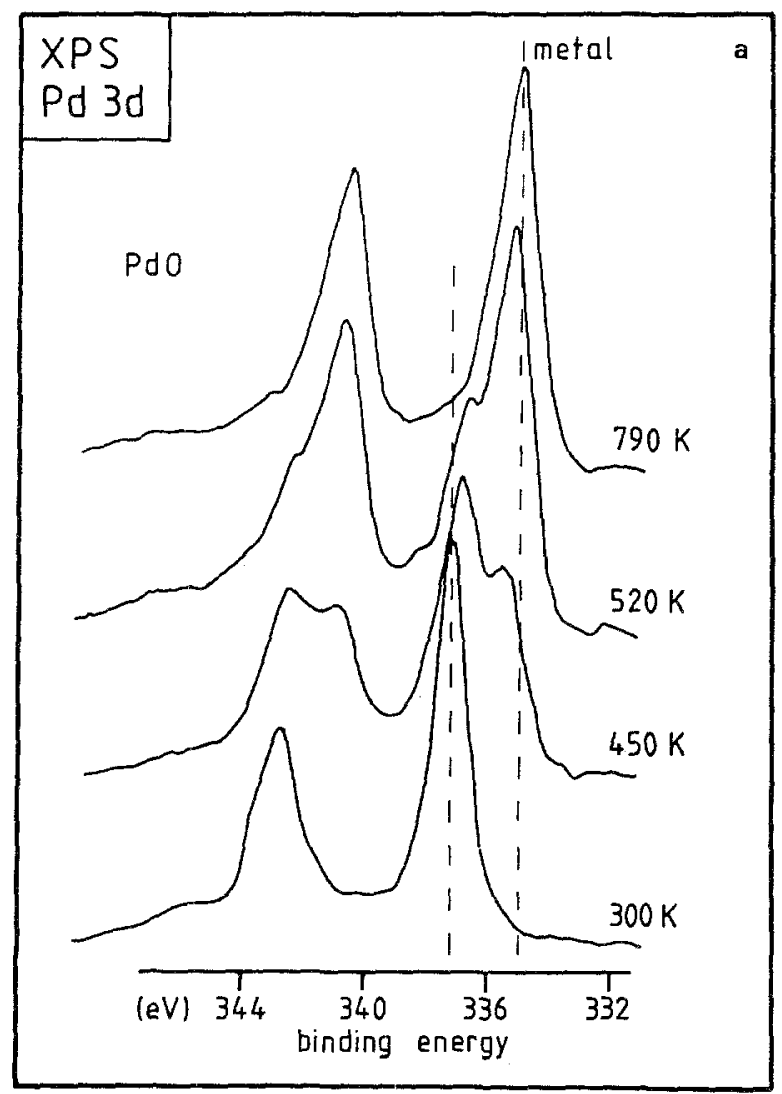

Fig. 3. a Pd 3d XPS of PdO heated in UHV at different temperatures. 


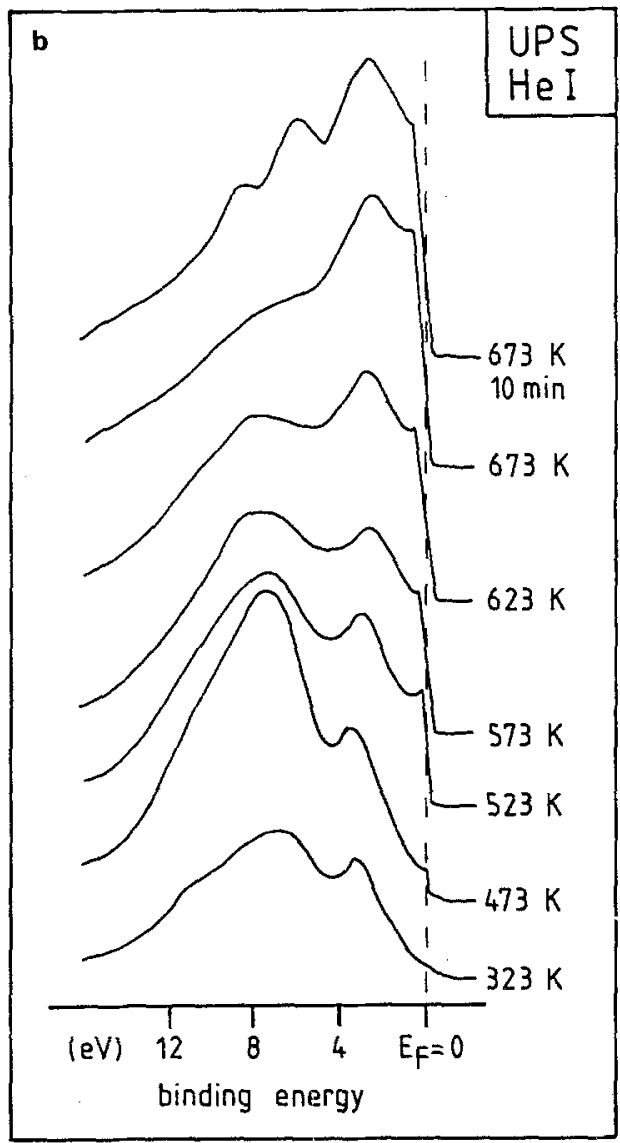

Fig. 3. b He I UPS of PdO heated in UHV taken at different temperatures.

The decomposition temperatures are somewhat lower than those reported on decomposition of a thick oxide overlayer on bulk Pd being 420 and $750-800 \mathrm{~K}$, respectively [14]. In this work an electrochemically oxidised Pd foil was heated in UHV with monitoring of the electron spectra. Analysis showed, that $\operatorname{Pd}(\mathrm{OH})_{2}$ must have been present at lower temperatures as the first decomposition peak of the present TPD experiments occurred. It transformed to give PdO; upon further heating, the oxide decomposed (second peak) but left behind oxygen as a solid solution of $\mathrm{O}$ in the Pd matrix. Removal of this oxygen occurred at even higher temperature (third peak).

Decomposition of the PdO particles was also followed by XPS: the spectra shown in fig. 3a clearly indicate the coexistence of Pd oxide and Pd metal during decomposition. The Pd oxide signal which shows a chemical shift of $+1.7 \mathrm{eV}$ relative to the metal does not only decrease in intensity but also shifts with ongoing decomposition. The metallic grains already produced prevent electrostatic charging as a possible reason for the shift. We conclude that the decomposi- 
tion occurs via an intermediate solid solution $\mathrm{Pd}+\mathrm{O}[14,15]$. Peak deconvolutions at different stages of decomposition gave good results with 3 contributions with energy shifts of 0.6 and $1.65 \mathrm{eV}$ relative to the line for Pd metal occurring at $335.5 \mathrm{eV}$.

The above conclusion is substantiated by corresponding UPS data shown in fig. $3 \mathrm{~b}$. The spectra indicate the formation of metallic Pd at a very early stage (Fermi edge appears) together with a changeover of the starting Pd oxybydroxide (Pd $4 \mathrm{~d}$ states broad at $3.6 \mathrm{eV}$ and $\mathrm{O} 2 \mathrm{p}$ derived features at $\sim 8$ and $11 \mathrm{eV}$ indicative of $\mathrm{OH}$ groups) into $\mathrm{PdO}$ forming at around $473 \mathrm{~K}$. This latter species decomposes gradually into $\mathrm{Pd}$ metal which is the only phase remaining at $673 \mathrm{~K}$. The broad intensity at $\sim 7 \mathrm{eV}$ is the indication for the dissolved oxygen which reacts with hydrogen present in $\mathrm{Pd}[16]$ to form $\mathrm{Pd}+\mathrm{OH}$ groups detectable after keeping the sample at $673 \mathrm{~K}$ for $10 \mathrm{~min}$.

Adding $\mathrm{Pb}$ to $\mathrm{PdO}$ resulted in roughly the same TPD peak structure with the second feature being significantly larger (fig. 1, curve 3 ). This indicates that the $\mathrm{Pb}$ compound present decomposes simultaneously with PdO. Since it was not

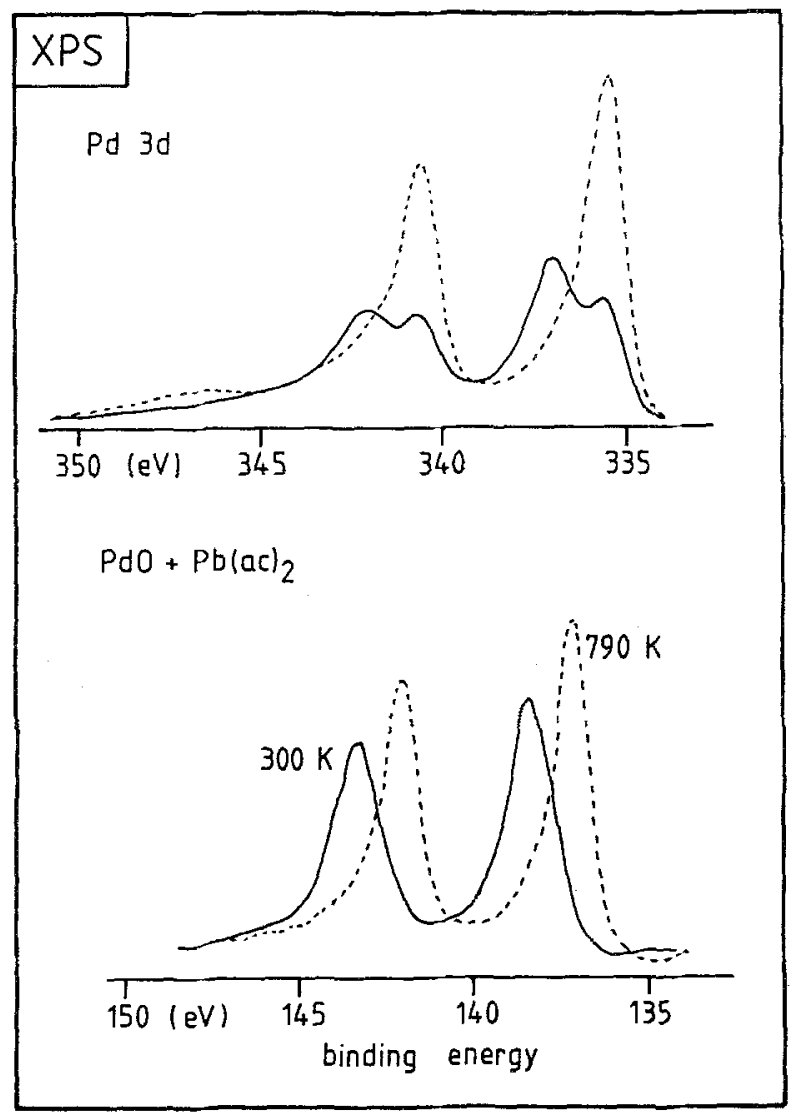

Fig. 4. $\mathrm{Pd} 3 \mathrm{~d}$ and $\mathrm{Pb} 4 \mathrm{f}$ spectra of a $\mathrm{PdO}$ sample loaded with lead acetate, spectra were taken at $300 \mathrm{~K}$ (full lines) and $790 \mathrm{~K}$ (dashed lines). 
possible to analyse the gas leaving the sample, it cannot be decided if the large peak contained the decomposition products of $\mathrm{Pb}$ (II) acetate or of $\mathrm{PbO}$. In fact, the decomposition of $\mathrm{Pb}$ acetate (to give $\mathrm{Pb}, \mathrm{CO}_{2}$ and $\mathrm{H}_{2} \mathrm{O}$ ) was reported to occur between 500 and $770 \mathrm{~K}$ [17].The decomposition of the $\mathrm{Pb}$ compound was also followed by XPS. Fig. 4 shows that only one Pb species can be detected as long as significant amounts of Pd oxide are present (high $\mathrm{BE}$ contributions in the Pd $3 d$ doublet). When the Pd oxide has entirely decomposed (dashed spectra), the lead compound is also transformed into the metallic state and the $\mathrm{Pb} 4 \mathrm{f}$ signal is shifted to lower BE values. Obviously, the presence of some Pd metal catalyses the acetate decomposition to be completed together with the PdO decomposition. The elemental ratio $\mathrm{Pd}: \mathrm{Pb}$ was found in this experiment to be around $10: 1$.

\section{SCANNING ELECTRON MICROSCOPY OF Pd}

Analytical electron microscopy of clean $\mathrm{Pd}$ and $\mathrm{Pd}+\mathrm{Pb}$ shows the presence of $\sim 1 \% \mathrm{~Pb}$ in the latter sample, whereas only $\mathrm{Pd}$ emissions were detected in the former case. Comparison with XPS data allow us to conclude that $\mathrm{Pb}$ is situated on the sample surface only and has not penetrated significantly into the bulk.

Scanning Electron Micrographs of $\mathrm{Pd}$ and $\mathrm{Pd}+\mathrm{Pb}$ at low magnifications show the presence of smooth faces of crystalline material with particle sizes of about 50 to $500 \mu \mathrm{m}$. At high magnifications a sponge-like microstructure built from spherical particles became apparent (fig. 5), analogous to that seen with $\mathrm{Pd}$ supported on $\mathrm{CaCO}_{3}$ [12]. Both samples showed essentially the same micromorphology; small differences in particle size should be due rather to the different number of hydrogen adsorption-desorption cycles than to the addition of $\mathrm{Pb}$.

\section{TEMPERATURE PROGRAMMED DESORPTION OF HYDROGEN FROM Pd}

The in-situ prepared $\mathrm{Pd}$ powder was loaded by heating in a hydrogen flow consisting of either pure $\mathrm{H}_{2}$ or of $\mathrm{H}_{2}-\mathrm{Ar}$ mixtures ( 5 to $50 \% \mathrm{H}_{2}$ ) up to $450 \mathrm{~K}$. After cooling to $100-150 \mathrm{~K}$, the gas stream was changed to pure $\mathrm{Ar}$ and a TPD experiment shown as a typical result in fig. $6 \mathrm{a}$ was carried out with a heating rate of $10 \mathrm{~K} / \mathrm{s}^{-1}$.

The switching over to Ar obscured the detection of any low temperature peak. Its presence can be guessed from a slight broadening of the switchover peak but the effect is below the resolution power of our detector system.

The first "real" TPD peak appeared as a very broad plateau starting at about $210 \mathrm{~K}$. Sometimes this feature was resolved into two subpeak structures: the main desorption started at about $290 \mathrm{~K}$. The shape of the spectrum resembled that observed on a $\mathrm{Pd}(100)$ single crystal [9].

The main desorption peak appeared with maxima between 325 and $380 \mathrm{~K}$. The data published by Konvalinka and Scholten [7] suggest the presence of three subpeaks; their values of desorption temperatures agree with the present observa- 

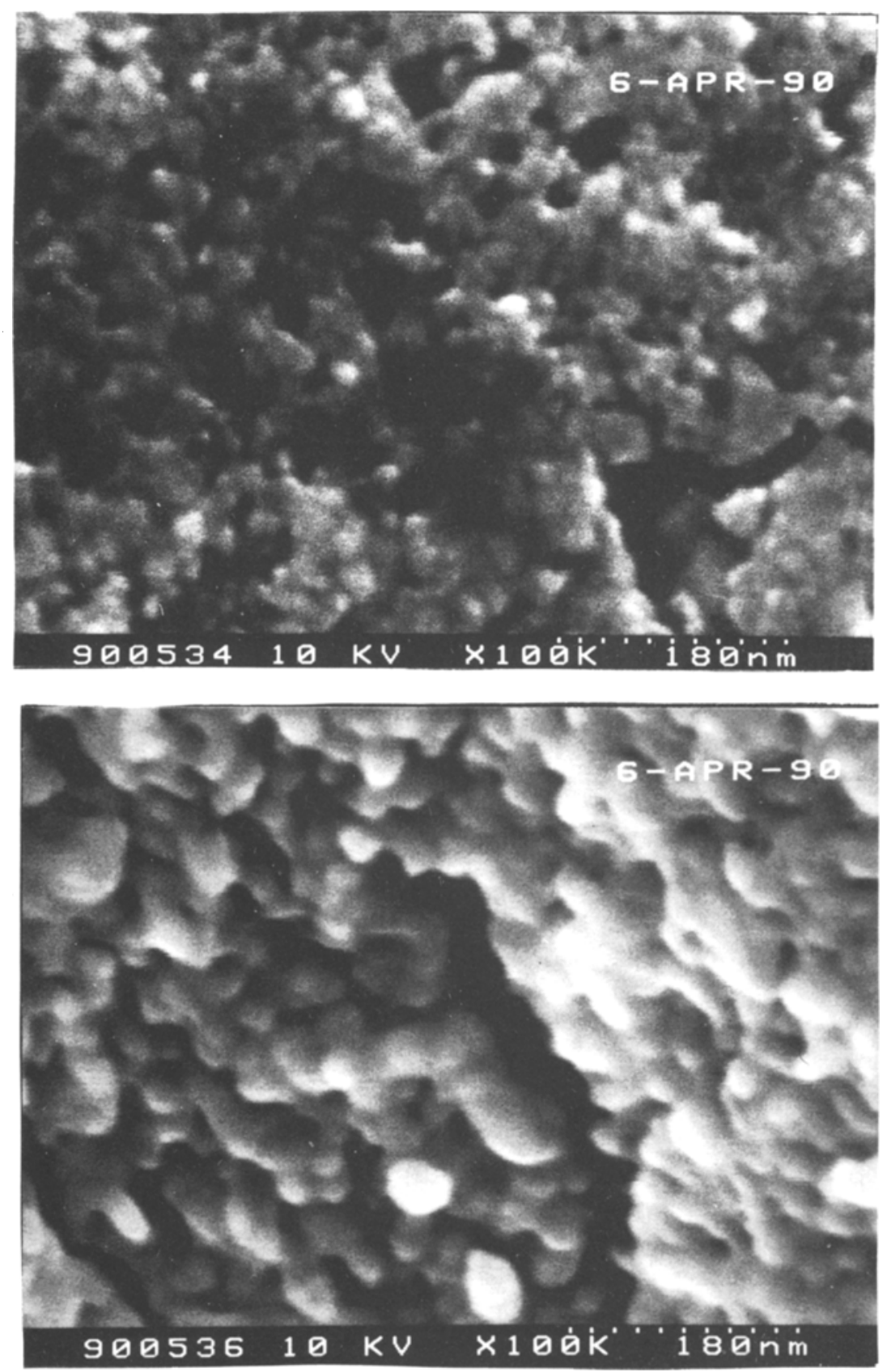

Fig. 5. Scanning Electron Micrographs of Pd surfaces without (a) and with (b) adding Pb.

tions. Adopting their denotion, we shall call the main feature "peak B". Although only two subpeaks within the main feature are visible in fig. 6 , further data will show that, in fact, three structures are present $(B / 1, B / 2$ and $B / 3)$. Diffusion 

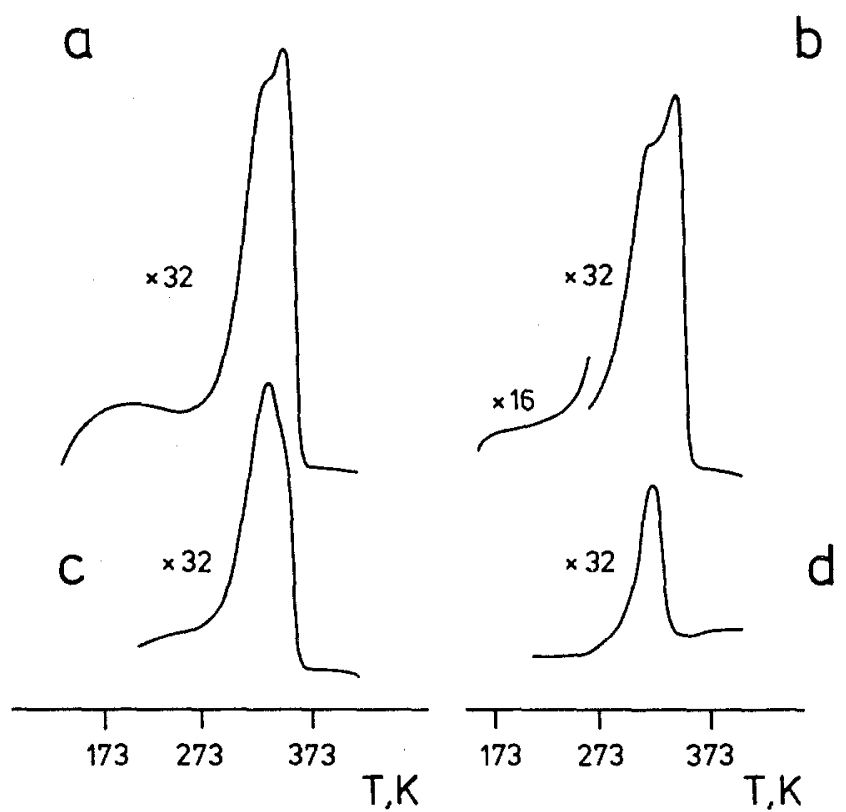

Fig. 6. TPD of hydrogen in Ar carrier gas $\left(50 \mathrm{~cm}^{3} \min ^{-1}\right.$ ) from pure $\mathrm{Pd}(\mathrm{a}$ and $\mathrm{b}$ ) and $\mathrm{Pd}+\mathrm{Pb}(\mathrm{c}$ and d). Hydrogen loading: flow of $20 \% \mathrm{H}_{2}$ in $\operatorname{Ar}\left(50 \mathrm{~cm}^{3} \mathrm{~min}^{-1}\right)$ with $10 \mathrm{~K} \mathrm{~min}^{-1}$ from $300 \mathrm{~K}$ to $420 \mathrm{~K}$ ( $\mathrm{a}$ and $\mathrm{c}$ ); the same concentration of hydrogen flow for $5 \mathrm{~min}$ at $130 \mathrm{~K}$ ( $\mathrm{b}$ and $\mathrm{d}$ ). The sample size was as in all experiments $8-10 \mathrm{mg}$.

effects prevent their complete separation in Ar. In addition, a small peak C ( $2 \%$ of peak B) was resolved at higher temperatures in agreement with ref. [7].

The detection of the described desorption pattern required at least once hydrogen loading above $300 \mathrm{~K}$. If the first loading was carried out at $130 \mathrm{~K}$, no hydrogen desorption was observed. If, however, a Pd sample which had seen once hydrogen at $400 \mathrm{~K}$ and, after removing hydrogen by TPD, was exposed to hydrogen for $5 \mathrm{~min}$ at $130 \mathrm{~K}$, the "plateau" was not observed but peak B appeared as before (fig. $6 \mathrm{~b}$ ). This means that population of the states desorbing as the broad low temperature feature require a higher thermal activation of about $300 \mathrm{~K}$ than population of the states desorbing as peak " $\mathrm{B}$ ". Under our conditions all states are completely depleted in one TPD run; successive runs also at other heating rates exhibit no further desorption features.

Adding $\mathrm{Pb}$ to $\mathrm{Pd}$ influenced first of all the population of individual subpeaks but not the temperatures of maximum desorption rates. Fig. $6 \mathrm{c}$ shows that with high-temperature loading, i.e., up to $420 \mathrm{~K}$, the area of the "plateau" as well as the concentration of the second subpeak (B/2 plus $B / 3)$ decreased drastically. On the other hand, with low-temperature loading (i.e., at $130 \mathrm{~K}$ ), only state $\mathrm{B} / 1$ was populated (fig. $6 \mathrm{~d}$ ).

A tentative identification of these peaks might be possible from experiments carried out with various heating rates. The application of ramps of 3 and $25 \mathrm{~K}$ 


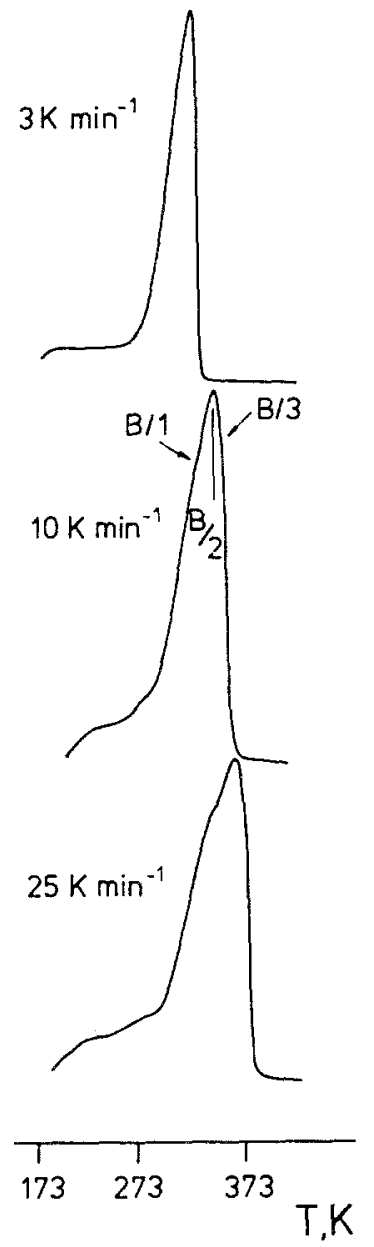

Fig. 7. Typical desorption spectra of hydrogen from decomposed PdO in Ar determined with different heating rates $\left(3,10\right.$ and $25 \mathrm{~K} \mathrm{~min}^{-1}$, respectively).

$\min ^{-1}$ showed essentially the same peak structure (fig. 7). The peak maxima were shifted to higher temperatures with increasing heating rate. This means that the desorption corresponds to a surface process with a reaction order higher than unity; no volume process was here involved. On the other hand, the shape and area under the "plateau" from $200 \mathrm{~K}$ disappeared completely with $3 \mathrm{~K} \mathrm{~min}^{-1}$ and was enhanced at $25 \mathrm{~K} \mathrm{~min}^{-1}$. This is indicative of a volume process which is equilibrated with the gas phase (or with surface hydrogen) at the lowest heating rate and appears as desorption feature as the deviation from equilibrium becomes larger with faster heating ramps. This assignment agrees with that given by Babenkova et al. [5].

TPD IN THE PRESENCE OF HYDROGEN

If a carrier gas of low hydrogen content is used during temperature programmed runs, not only gas desorption but eventual gas uptake can be moni- 


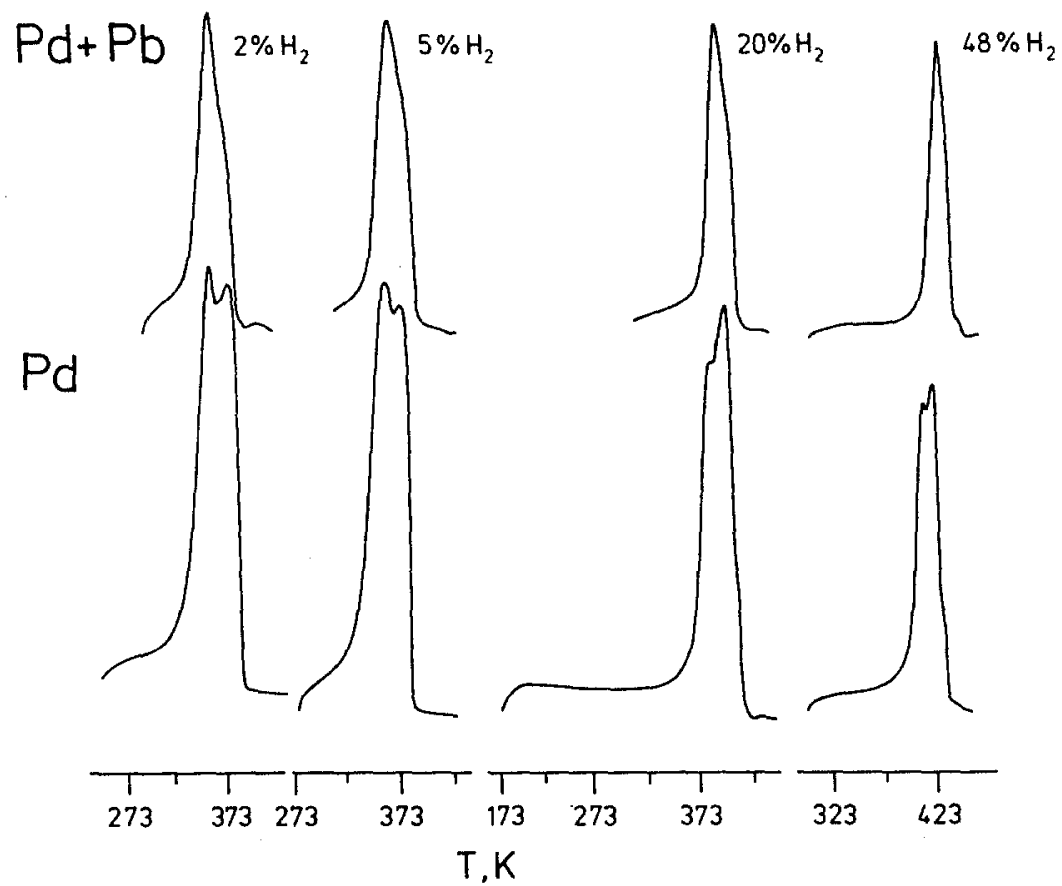

Fig. 8. Lower curves (series a): $\mathrm{Pd}$; upper curves (series b): $\mathrm{Pd}+\mathrm{Pb}$. Hydrogen TPD with varying partial pressures of hydrogen in the carrier gas (total flow $50 \mathrm{ml} \mathrm{min}^{-1}$ ).

tored. Menon and Froment [18] reported desorption and adsorption peaks with cycling their $\mathrm{Pt}$ catalysts in carrier gases with different $\mathrm{H}_{2}$ content.

In our case, as the hydrogen content in Ar increased from zero to $48 \%$ (concentrations of $2 ; 5 ; 10 \%$ were applied), narrower peaks appeared since the surface was always closer to the gas-solid equilibrium in the presence of hydrogen gas. No hydrogen uptake was observed. The desorption peak maxima were shifted towards higher temperatures. This is obvious since hydrogen leaving the surface met a gas environment of increasing hydrogen content. With different heating rates ( 3 and $25 \mathrm{~K} \mathrm{~min}^{-1}$ ), the shape of the peaks system remained unchanged and so did the approximate ratios of the components.

These experiments revealed that peak B may, indeed, be divided into three rather than two subpeaks (fig. 8). With this separation being more complete in the pure carrier gas experiments it emerged that what was identified as one second subpeak of structure $B$ was in fact a combination of $B / 2$ and $B / 3$. Desorptions from $B / 1$ and $B / 3$ states decreases with increasing hydrogen concentration in the carrier gas.

In the presence of added $\mathrm{Pb}$ the desorption temperatures from the $\mathrm{B} / 1$ population was always identical to that of the pure Pd samples. This is considered as a sensitive indication that the electronic structure of the chemisorption sites in both samples are identical which is in full agreement to the $\mathrm{CO}$ chemisorption 
experiments described in ref. [12]. The addition of $\mathrm{Pb}$ changes, however, clearly the relative population of the surface species: $B / 1$ remains unaffected, $B / 2$ is reduced and $B / 3$ is completely supressed. These changes do not depend on the hydrogen concentration. This is the first positive evidence for a direct influence of the lead modifier on hydrogen chemisorption at polycrystalline $\mathrm{Pd}$.

\section{Discussion}

The present work utilises a model system close to real hydrogenation catalysts and identifies under practical hydrogenation conditions various chemisorbed states of hydrogen which in part agree with earlier observations on different Pd systems.

PdO decomposes in three steps: one corresponds to the decomposition of $\operatorname{Pd}(\mathrm{OH})_{2}$, the second to that of PdO while the third step is the removal of dissolved oxygen. Both TPD and photoemission support this interpretation. This characterisation serves as the basis for a defined in-situ preparation of $\mathrm{Pd}$ particles. Both UPS and TPD experiments show that these particles chemisorb oxygen which does not, however, oxidise the metal to PdO under the conditions of our experiments. The state of $\mathrm{Pd}+\mathrm{O}$ is probably typical for many $\mathrm{Pd}$ metal systems which were calcined at elevated temperatures or stored in air. It requires significant efforts of cyclic hydrogenation and annealing under UHV to remove the oxygen from any palladium metal (foil, powder, black, single crystal).

The $\mathrm{Pd}+\mathrm{O}$ state still chemisorbs and dissolves hydrogen which can produce at elevated temperatures hydroxyl and water in a solid state mediated $\mathrm{H}+\mathrm{O}$ reaction.

In hydrogen TPD the low temperature desorption plateau corresponds to the decomposition of bulk hydrogen as suggested in ref. [5]. The fact that it is absent with hydrogen loading at $130 \mathrm{~K}$ supports this hypothesis since this temperature is not high enough to produce a hydride phase. Addition of $\mathrm{Pb}$ considerably decreases the amount of hydride likely by blocking key surface positions serving as "gates" for hydrogen penetration into sub-surface regimes which is an early step in the process of hydride formation from $\mathrm{H}_{2}$ gas and Pd metal [19].

The main desorption peak, $\mathrm{B}$ arises from removal of chemisorbed hydrogen from the surface. It is produced by recombination of atomic hydrogen with its order of desorption kinetics being higher than unity. Three subpeaks constituting the whole feature $\mathrm{B}$ correspond to recombination of hydrogen from various sites. A possible location of these sites follows the suggestions of Konvalinka and Scholten [7] and Eley and Pearson [16] that one of the hydrogen sites corresponds to octahedral holes below the surface. The recombination of one $\mathrm{H}$ atom in this position with a surface species may require lower activation energy than that of two surface $\mathrm{H}$ atoms in neighbouring "valley" positions [7]. 
The three desorption features may thus result from recombination processes of subsurface $\mathrm{H}$-atoms with several surface species. Lead atoms may block sites with high coordination numbers and so reduce the population of hydrogen with high chemisorption energy.

An alternative scenario takes into account that the Pd surface contains a large number of defects as steps, kinks, islands of impurities (of sulfur or silicate) etc. which remain uncharacterised on these polycrystalline particles. The absence of a surface state feature in UPS points to such a disordered surface. Different desorption energies from this heterogeneous surface would then reflect the particular state of ordering of the particle surface. This parameter was certainly different in the various studies mentioned. In the introduction, offering an explanation for the discrepances of the experimental data. Lead affects preferentially the defect sites and so suppresses the high energy hydrogen desorption features. A more profound interpretation requires a microstructural characterisation of the substrate which is now under way.

In conclusion, this work has clearly illustrated that the lead modifier of the Lindlar catalyst affects the distribution of chemisorption sites for surface hydrogen and reduces the tendency to hydride formation. The substrate used was-in agreement with practical catalyst preparation-palladium metal with residual oxygen being dissolved in small quantities in the lattice.

The dissolved atoms reduce the density of states at the Fermi edge and thus influence the hydrogen chemisorption in a difficult to control way. Preliminary UPS/XPS results on palladium/carbon systems showed that low temperature hydrogen reduction without thermal treatment above $400 \mathrm{~K}$ also lead to $\mathrm{Pd}+\mathrm{O}$. The presence of this difficult to detect material offers understanding of the pronounced sensitivity of Pd hydrogenation catalysts for preparation details and storage.

These findings have been obtained on realistic model surfaces and may be of relevance for the operation of selective hydrogenation catalysts $[1,12]$. The addition of lead modifies the surface in a way that sites which either contain highly reactive hydrogen for nonselective hydrogenation or act as adsorption centers for e.g. the primary (selective) hydrogenation product are rendered unavailable at temperatures of practical hydrogenations. These temperatures coincide roughly with the surface hydrogen desorption features. Any effect of $\mathrm{Pb}$ on the electronic structure of Pd is not supported by the TPD observations. In particular, there is no "special" hydrogen species created at the surface of Pd modified by lead.

It is pointed out that no direct correlation should be drawn between any of the three surface species and the species active in selective hydrogenation due to the unknown interferences of $\mathrm{CO}$ adsorption effects of hydrogen and the organic substrates. 


\section{References}

[1] H. Lindlar, Helv. Chim. Acta 35 (1952) 446.

[2] F. Greuter, I. Strathy, E.W. Plummer and W. Eberhardt, Phys. Rev. B 33 (1986) 736.

[3] R.J. Cvetanovic and Y. Amenomiya, Adv. Catal. 17 (1967) 103.

[4] G.C. Bond, Catalysis by Metals (Academic Press, New York, London, 1962).

[5] L.V. Babenkova, N.M. Popova, D.V. Sokolskii and V.K. Solnyshkova, Dokl. Akad. Nauk SSSR 210 (1973) 888.

[6] A.W. Aldag and L.D. Schmidt, J. Catal. 22 (1971) 260.

[7] J.A. Konvalinka and J.J.F. Scholten, J. Catal. 48 (1977) 374.

[8] M.G. Cattania, V. Penka, R.J. Behm, K. Christmann and G. Ertl, Surf. Sci. 126 (1983) 382.

[9] R.J. Behm, K. Christmann and G. Ertl, Surf. Sci. 99 (1980) 320.

[10] W. Palczewska, J. Jablonski and Z. Kaszkur, J. Mol. Catal. 25 (1984) 307.

[11] R. Schlögl, K. Noack, H. Zbinden and A. Reller, Helv. Chim. Acta 70 (1987) 627.

[12] W. Verhoven and B. Delmon, Bull. Soc. Chim. France, 3065 (1986).

[13] M. Peuckert, J. Phys. Chem. 89 (1985) 2481.

[14] K. Noack, H. Zbinden and R. Schlögl, Catal. Lett. 4 (1990) 145.

[15] D.D. Eley and E.J. Pearson, J. Chem. Soc. Faraday Trans. 1, 74 (1978) 223.

[16] Gmelin's Handbuch der anorganischen Chemie, Pb, System, Nr. 47, Vol. C/2 (Verlag Chemie, Weinheim/Bergstr.) p. 742.

[17] P.G. Menon and G.F. Froment, Appl. Catal. 1 (1981) 31.

[18] T.P.R. Gibb, in: Progress in Inorganic Chemistry, ed. F.A. Cotton (Interscience, New York, 1962) Vol. 3, p. 315. 